Author's Conrtibution

A - Study Design

B - Data Collection

C - Statistical Analysis

D - Data Interpretation

E - Manuscript Preparation

$F$ - Literature Search

$\mathrm{G}$ - Funds Collection

\section{The Impact of 32 Days' Exposure to Hypobaric Hypoxia on Physiological Cost of Sub-Maximal Work Performed at the Sea Level}

\author{
Sylwester Kujach ${ }^{1(A, B, C, D, F)}$, Tomasz Grzywacz ${ }^{1,2(A, B, C, D, D, E, F)}$, \\ Ewa Ziemann ${ }^{3(A, B, C, F)}$, Robert Szymczak ${ }^{4(A, B, F)}$, \\ Marcin Łuszczyk ${ }^{1(\mathrm{~A}, \mathrm{~B}, \mathrm{C}, \mathrm{F})}$, Radosław Laskowski ${ }^{1,2(\mathrm{D}, \mathrm{E}, \mathrm{F})}$ \\ ${ }^{1}$ Jedrzej Sniadecki Academy of Physical Education and Sport \\ in Gdansk, Department of Physiology, Poland \\ ${ }^{2}$ Kazimierz Górski Higher School of Sports, Lodz, Poland \\ ${ }^{3}$ Warsaw School of Social Sciences and Humanities, Department \\ of Physiotherapy, Sopot, Poland \\ ${ }^{4}$ Medical University of Gdansk, Clinical Department of Emergency \\ Medicine, Poland
}

Key words: hypobaric hypoxia, high altitude, metabolic cost

Background: Many papers showed that long-lasting exposure to hypobaric hypoxia changed the metabolic cost of work and substrate contribution, elevating exercise energy expenditure and carbohydrates utilization. Only few of them have shown how long this adaptive changes are maintained. The aim of the study was to assess the impact of prolonged sojourn at high altitude on the physiological cost of sub-maximal work performed at the sea level.

Materials and methods:

Eight members of two high altitude expeditions (Lenin Peak 7,134 $\mathrm{m}$ a.s.l. and Somoni Peak 7,495 $m$ a.s.l.), 7 males and 1 female, mean age 26 ( \pm 4.1$)$ years, volunteered for this study. Aerobic performance was measured by a direct method (breath-by-breath) using an expiratory gas analyser (Oxycon Pro, Jaeger) with an incremental exercise test till exhaustion. The sea level examinations were performed 7 days before the expedition (BEx) and 7 days after (AEx) the last day at over 2,500 $m$ a.s.l. Participants spent $32( \pm 3)$ days over 2,500 $\mathrm{m}$ a.s.l. at the mean altitude of 4,712 $\mathrm{m}$ a.s.l. ( $\pm 499 \mathrm{~m}$ ).

Results: Prolonged sojourn at high altitude has changed the ventilatory parameters of submaximal work measured at the sea level. The sojourn resulted in an increase in the ventilatory volume (tidal volume, minute ventilation and breath frequency) during the sub-maximal work performed with the same workload. However, the respiratory exchange ratio remained at a high level compared to the baseline.

Conclusions: We suggest that the adaptive changes introduced during the sojourn remain at the sea level and cause increased carbohydrate metabolism.

Word count: $\quad 1634$

Tables: $\quad 1$

Figures: $\quad 8$

References: $\quad 18$
Received: November 2010

Accepted: December 2011

Published: $\quad$ March 2011

Address for correspondence

Dr hab. Radosław Laskowski, prof. nadzw., Academy of Physical Education and Sport, Department of Physiology,

80-336 Gdańsk, Poland, ul. K. Górskiego 1, Phone: +4858 554-74-82, e-mail: lasradek@awf.gda.pl 


\section{Background}

Many papers showed that chronic exposure to hypobaric hypoxia changed the metabolic cost of work [1] and substrate contribution [2] during efforts performed at the sea level, elevating exercise energy expenditure and carbohydrates utilization [3,4]. Holloway et al. [5] postulated that changes in cardiac high-energy phosphate metabolism may underlie the myocardial dysfunction caused by hypobaric hypoxia. Cardiac response to hypobaric hypoxia resulted in persistent changes in cardiac mass, function, and energy metabolism after trekking to Mt. Everest Base Camp. According to Esposito et al. [6], theoretical models of $\mathrm{VO}_{2 \max }$ limitation seem to contradict the lack of $\mathrm{VO}_{\text {max }}$ increase in hypoxia, suggesting a possible role of increased ventilation-perfusion mismatch. This may also affect the ability to perform physical exercise after returning to the sea level.

Hypobaric hypoxia affects cerebrovascular responses to incremental exercise and results in cerebral deoxygenation at maximal intensity. Cerebral oxygenation appears to be an important variable influencing fatigue under hypobaric hypoxia, since the reversal of cerebral deoxygenation at maximal exertion was associated with increased performance [7].

Functional analyses revealed positive effects on $\mathrm{VO}_{2 \max }$ (when measured at altitude) on the maximal power output and on lean body mass. In addition to the positive effects of hypoxia training on athletic performance, there is some recent indication that hypoxia training has a positive effect on the risk factors for cardiovascular diseases [8].

Some authors suggest that hypobaric hypoxia does not influence adaptation changes in a statistically significant way while performing sub-maximal efforts $[9,10]$. Other authors write that the adaptations abilities could significantly change during such efforts $[11,12]$.

Due to this fact, the aim of the study was to assess the impact of a prolonged sojourn at high altitude on the physiological cost of sub-maximal work performed at the sea level.

\section{Material and Methods}

\section{Subjects}

Eight members of high altitude expeditions to Lenin Peak 7,134 m a.s.I. and Somoni Peak $7,495 \mathrm{~m}$ a.s.l., 7 males and 1 female, mean age $26( \pm 4.1)$ years, volunteered for this study. Physical characteristics of the examined group (mean \pm SD) are shown in Table 1. The sea level examinations were performed 7 days before the expedition (BEx) and 7 days after (AEx) the last day at over 2,500m a.s.I. Participants spent $32( \pm 3)$ days at over 2,500m a.s.l. at the mean altitude of $4,712 \mathrm{~m}$ a.s.l. $( \pm 499 \mathrm{~m})$ (Fig. 1$)$.

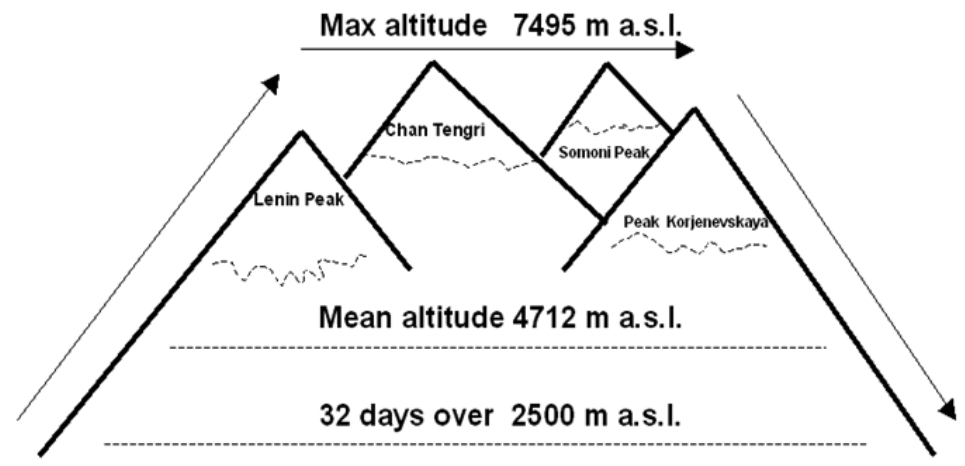

Fig. 1. Study design of high altitude expeditions (Lenin Peak 7,134m a.s.I. and Somoni Peak 7,495m a.s.I. 
Considering a similar character of the two expeditions - siege mountaineering expedition for two 7,000m peaks, altitudes of the base camps and average periods of altitude sojourn, the two groups of alpinists were analysed together.

All volunteers gave informed consent to participate in the study which was approved by the Medical University of Gdansk Regional Ethics Committee.

\section{Anthropometric measurements}

Body mass $(\mathrm{BM})$ and body composition were estimated using a bioelectrical impedance floor scale (TBF-300 Body Fat Monitor/Scale Analyzer, Tanita, Japan) calibrated in accordance with the manufacturer's guidelines prior to each test session. One hour following a light breakfast, participants voided their bladders and bowels and, clad only in briefs, underwent duplicate measures in the standing position recommended by the manufacturer's guidelines. The following parameters were assessed: body mass [kg]; (FAT) - fat mass - [kg] and [\%]; (FFM) - fat free mass - $[\mathrm{kg}]$; (TBW) - total body water - $[\mathrm{kg}]$; (BMI) - body mass index - $\left[\mathrm{kg} \cdot \mathrm{m}^{-2}\right]$ and also (BMR) - basic metabolic rate $-\left[\mathrm{kcal} \cdot 24 \mathrm{~h}^{-1}\right]$. All results are presented in Table 1.

Sub-maximal exercise and $\mathrm{VO}_{2 \max }$ test was performed on a cycloergometer ER900 (JaegerViasys, Germany). This test started at 2 min of resting phase in the seating position, and then turned to 6 min test phase at the power output of $1.5 \mathrm{~W} \cdot \mathrm{kg}^{-1}$ with a pedalling rate of $50 \mathrm{rev} \cdot \mathrm{min}^{-1}$; the participants began cycling at workloads increased by $25 \mathrm{~W} \cdot \mathrm{min}^{-1}$ until volitional exhaustion. During the test the following parameters were continuously monitored: $\left(\mathrm{VO}_{2}\right)$ - oxygen uptake - $\left[\mathrm{mL} \cdot \mathrm{kg}^{-1} \cdot \mathrm{min}^{-1}\right],\left[\mathrm{L} \cdot \mathrm{min}^{-1}\right] ;\left(\mathrm{VCO}_{2}\right)$ - carbon dioxide excretion $-\left[\mathrm{mL} \cdot \mathrm{kg}^{-1} \cdot \mathrm{min}^{-1}\right],\left[\mathrm{L} \cdot \mathrm{min}^{-1}\right] ;(\mathrm{RER})$ - respiratory exchange ratio; (VE) - minute ventilation - [L· $\left.\min ^{-1}\right]$; (VT) - tidal volume [L]; (BF) - breath frequency [rpm]; (HR) - heart rate [bpm]; an expiratory gas analyser Oxycon Pro of Jaeger and computer software Breath-by-Breath were used.

\section{Statistical analysis}

Statistical analyses were performed using STATISTICA software 7.0 (StatSoft, USA). The differences between results of physical performance and body composition at the sea level before and after the expeditions were analyzed using Student's t-test. The level of statistical significance (p) was set at 0.05 .

Tab. 1. Anthropometric characteristics of the examined group

\begin{tabular}{|l|c|c|}
\hline \multicolumn{1}{|c|}{$\mathrm{N}=\mathbf{8}$} & Before the expedition & After the expedition \\
\hline Age $(\mathrm{y})$ & $26.0 \pm 4.2$ & $26.0 \pm 4.2$ \\
\hline Height $(\mathrm{cm})$ & $177.0 \pm 6.0$ & $177.0 \pm 6.0$ \\
\hline Body $\mathrm{mass}(\mathrm{kg})$ & $71.0 \pm 8.7$ & $69.9 \pm 9.0$ \\
\hline VO $_{2 \max }\left(\mathrm{mL} \cdot \mathrm{min}^{-1} \cdot \mathrm{kg}^{-1}\right)$ & $49.9 \pm 6.3$ & $46.1 \pm 5.7$ \\
\hline FAT $(\%)$ & $13.8 \pm 3.5$ & $11.4 \pm 3.8^{*}$ \\
\hline FAT $(\mathrm{kg})$ & $9.8 \pm 2.5$ & $7.8 \pm 2.0 *$ \\
\hline FFM $(\mathrm{kg})$ & $61.3 \pm 8.0$ & $62.0 \pm 9.5$ \\
\hline BMI $\left(\mathrm{kg} \cdot \mathrm{m}^{-2}\right)$ & $22.4 \pm 2.1$ & $22.1 \pm 2.1$ \\
\hline BMR $\left(\mathrm{kcal} \cdot 24 \mathrm{~h}^{-1}\right)$ & $1745.1 \pm 181.5$ & $1728.5 \pm 188.6$ \\
\hline TBW $(\mathrm{kg})$ & $44.9 \pm 5.9$ & $45.4 \pm 6.9$ \\
\hline
\end{tabular}

$\mathrm{FAT}=$ fat mass; $\mathrm{FFM}$ = free fat mass; $\mathrm{BMI}=$ body mass index; $\mathrm{BMR}=$ basal metabolic rate; $\mathrm{TBW}$ = total body water; Values are means $\pm S D ;{ }^{*}$ Significant differences $(p<0.05)$ vs. before expedition 


\section{Results}

Seven days after a high altitude expedition (32 days at over 2,500m a.s.I.) we observed statistically significant $(p<0.005)$ differences of time (vs before the expedition) in some cardio-respiratory parameters. The obtained data showed a significant increase $(p<0.05)$ in mean values of the heart rate $-\mathrm{HR}_{\text {stst }}[\mathrm{bpm}](124 \pm 16$ vs $130 \pm 11)$ and minute ventilation $-\mathrm{VE}_{\text {stst }}$ [L min ${ }^{-1}$ ] (38.2 \pm 6.6 vs $48.1 \pm 8.1)$ during sub-maximal effort, for the pre- and post-expedition measurements respectively. Figures 2 and 3 present these differences.

We also observed an increase in tidal volume $-\mathrm{V}_{\text {Tstst }}[\mathrm{L}](1.99 \pm 0.61$ vs $2.14 \pm 0.46)$ and breath frequency $-B F_{\text {sts }}\left[1 \mathrm{~min}^{-1}\right](21 \pm 7-23 \pm 5)$, but this increase was statistically insignificant. Figures 4 and 5 present these variables.

Additionally, as shown in Figures 6 and 7, there were statistically significant changes in the respiratory exchange ratio - $\operatorname{RER}_{\text {stst }}(0.87 \pm 0.04$ vs $1.02 \pm 0.08)$ and carbon dioxide production - $\left.\mathrm{VCO}_{2 \text { stst }}\left[\mathrm{mL} \cdot \mathrm{min}^{-1}\right]\right)(1459.6 \pm 191.5 \mathrm{vs} 1728.0 \pm 323)$, which may indicate an increased use of carbohydrates and an increase in the physiological cost of work. There are no similar significant differences in oxygen consumption $-\mathrm{VO}_{2 \text { stst }}\left[\mathrm{mL} \cdot \mathrm{min}^{-1}\right](1676.6 \pm 170.6$ vs $1709.5 \pm 327.8)$.

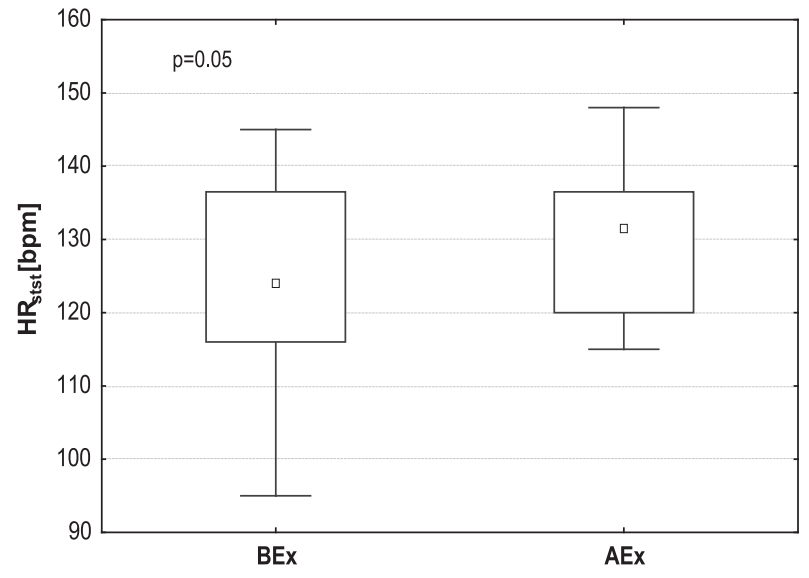

Fig. 2. Heart rate $-H_{\text {stst }}(\mathrm{bpm})$ during sub-maximal effort before (BEx) and after (AEx) the expedition

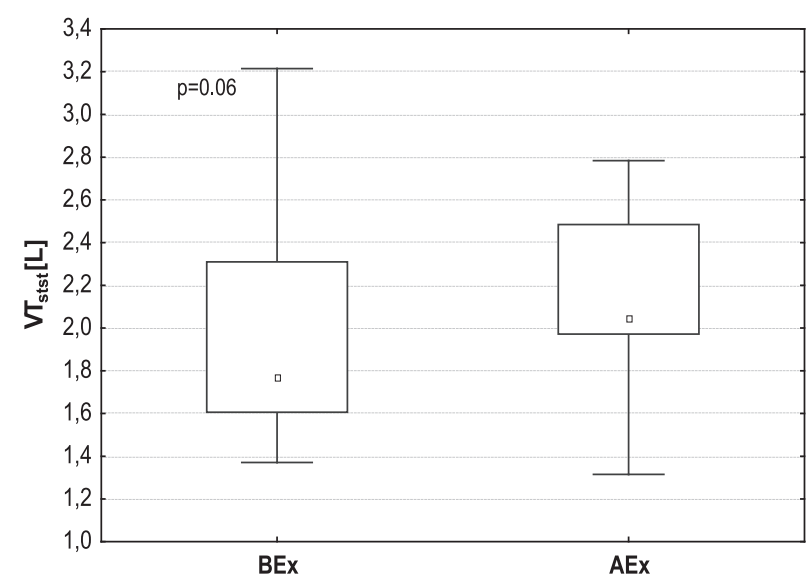

Fig. 4. Tidal volume $\left(V T_{\text {stst }} L\right)$ during sub-maximal effort before (BEx) and after (AEx) the expedition

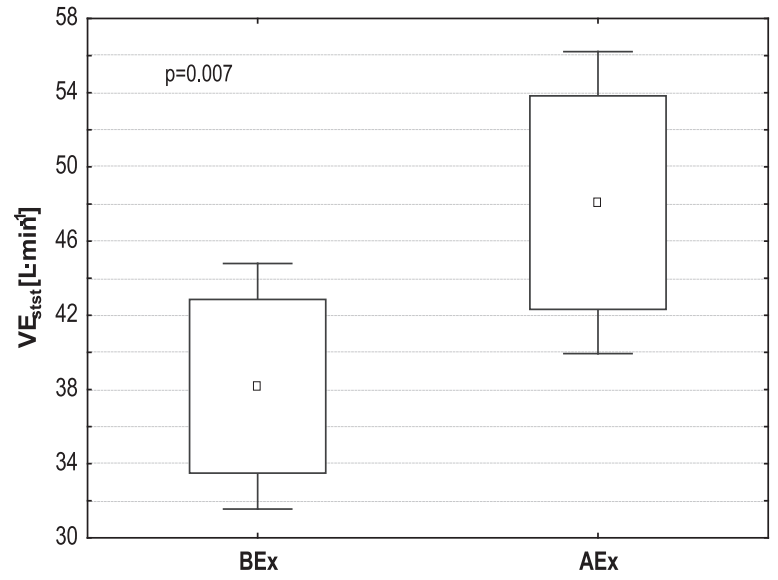

Fig. 3. Minute ventilation $-V E_{\text {stst }}\left(L \cdot \min ^{-1}\right)$ during sub-maximal effort before (BEx) and after (AEx) the expedition

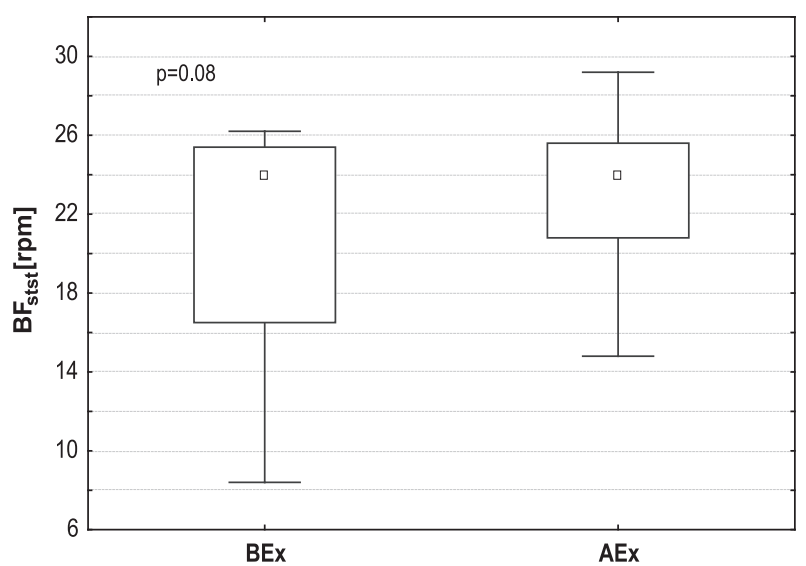

Fig. 5. Breath frequency $-B F_{\text {stst }}(\mathrm{rpm})$ during sub-maximal effort before (BEx) and after (AEx) the expedition 




Fig. 6. Respiratory Exchange Ratio (RERstst) during submaximal effort before (BEx) and after (AEx) the expedition

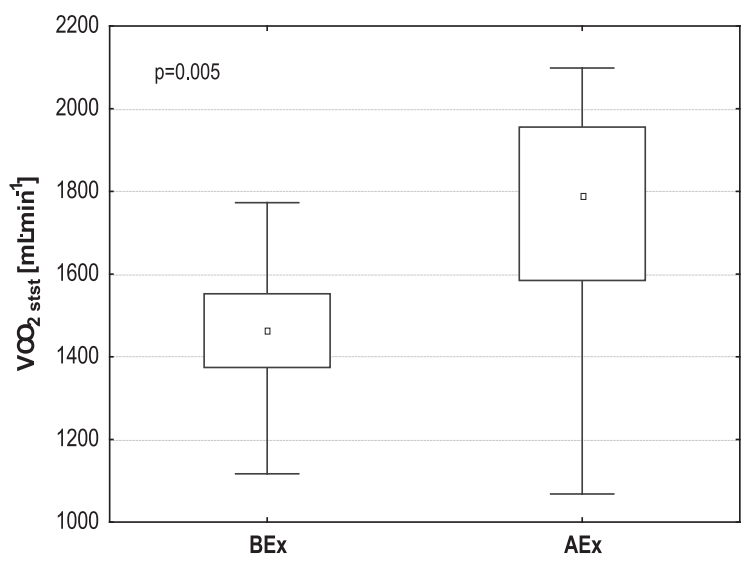

Fig. 7. Carbon dioxide production $\left(\mathrm{VCO}_{2}\right.$ stst $\left.\mathrm{mL} \cdot \mathrm{min}^{-1}\right) \mathrm{du}-$ ring sub-maximal effort before (BEx) and after (AEx) the expedition



Fig. 8. Oxygen consumption $\left(\mathrm{VO}_{2 \text { stst }} \mathrm{mlkg}^{-1} \cdot \mathrm{min}^{-1}\right)$ during sub-maximal effort before (BEx) and after (AEx) the expedition

\section{Discussion}

The aim of the present study was to assess the impact of a prolonged sojourn at high altitude on the metabolic cost of sub-maximal work performed at the sea level.

It was demonstrated that high altitude expeditions (32 days in the mountains at over $2,500 \mathrm{~m}$ a.s.I. on the mean altitude of $4,712 \mathrm{~m}$ a.s.I.) have an impact on changes in adaptations of submaximal work performed at the sea level.

In our study the specific parameter of a human's aerobic capacity $\mathrm{VO}_{2 \max }$ decreased but not to statistically significant degree (Tab 1). This is confirmed by other authors $[11,13]$. Therefore, it appears that repeated short-term exposures to hypoxia during intense physical training do not significantly contribute to the mechanisms responsible for the improvements in aerobic performance observed at the sea level.

After high altitude expeditions we observed a reduction in the total body weight in our tested subjects. This happened at the expense of a statistically significant decrease in FAT (Tab. 1).

The obtained data showed a statistically significant increase in the heart rate during sub-maximal effort (Fig. 2). This might have occured as a result of changes in pressure in the heart. According to Holloway et al. [5], within 4 days of return from 17-day trekking to Mt. Everest Base Camp $(5,300 \mathrm{~m})$ the total body weight in the tested people had fallen by $3 \%$, but left ventricular mass, adjusted for changes in body surface area, had disproportionately decreased by $11 \%$ $(p<0.05)$. Acute hypoxia in spontaneously breathing anaesthetized animals caused increases in 
sympathetic nerve activity, increased release of catecholamines, increases in the heart rate and regional vasoconstriction [14,15]. However, the effects of hypoxia on the human sympathetic nervous system are more difficult to determine, and often indirect methods of assessment have been employed.

A sojourn at high altitudes stimulates incremental physiological cost of work in respiratory muscles. Nervous and chemical regulation of breath should decrease ventilatory parameters after returning to the sea level $[16,17]$, contrary to what has been observed. This is determined by a statistically significant increase in minute ventilation (Fig. 3) during sub-maximal effort after 7 days of high altitude expeditions. Tidal volume (Fig. 4) and breath frequency (Fig. 5) increase, but in a statistically insignificant way.

At the same time, many authors suggest that growth factors such as HIF-1 $\alpha$ and TNF- $\alpha$ lead to increased carbohydrates metabolism [8, 18]. A higher level of RER (due to an increase in the value of carbon dioxide and equal to oxygen uptake) after mountain trekking in our participants suggested the retained increased carbohydrate metabolism (Fig. 6).

\section{Conclusions}

Prolonged sojourn at high altitude changed the ventilatory parameters of sub-maximal work measured at the sea level. However, the respiratory exchange ratio remained at the high level according to the baseline. We suggest that the adaptive changes introduced during the sojourn remain at the sea level and cause increased carbohydrate metabolism and elevated total physiological cost of work.

\section{Conflict of interest}

There are no conflicts of interest to be reported by the authors, as there are no professional relationships with companies or manufacturers who will benefit from the results of the present study.

\section{References}

1. Hochachka PW, Bianconcini MS, Parkhouse WS, Dobson GP. On the role of actomyosin ATPases in regulation of ATP turnover rates during intense exercise. Proc Natl Acad Sci USA 1991;88(13):5764-8.

2. Péronnet $F$, Massicotte $D$, Folch $N$, et al. Substrate utilization during prolonged exercise with ingestion of (13)Cglucose in acute hypobaric hypoxia (4,300 m). Eur J Appl Physiol 2006;97(5):527-34.

3. Kelly KR, Williamson DL, Fealy CE, et al. Acute altitude-induced hypoxia suppresses plasma glucose and leptin in healthy humans. Metabolism 2010;59(2):200-5.

4. Roberts AC, Reeves JT, Butterfield GE, et al. Altitude and beta-blockade augment glucose utilization during submaximal exercise. J Appl Physio/1996;80(2):605-15.

5. Holloway CJ, Montgomery HU, Murray AJ, et al. Caudwell Xtreme Everest Research Group. Cardiac response to hypobaric hypoxia: persistent changes in cardiac mass, function, and energy metabolism after a trek to Mt. Everest Base Camp. FASEB J 2010 Oct 26. [Epub ahead of print]

6. Esposito F, Limonta E, Alberti G, Veicsteinas A, Ferretti G. Effect of respiratory muscle training on maximum aerobic power in normoxia and hypoxia. Respir Physiol Neurobiol 2010;170(3):268-72.

7. Subudhi AW, Lorenz MC, Fulco CS, Roach RC. Cerebrovascular responses to incremental exercise during hypobaric hypoxia: effect of oxygenation on maximal performance. Am J Physiol Heart Circ Physiol 2008;294(1):16471.

8. Hoppeler H, Vogt M. Muscle tissue adaptations to hypoxia. J Exp Biol 2001;204(18):3133-3139.

9. Emonson DL, Aminuddin AH, Wright RL, Scroop GC, Gore CJ. Training induced increases in sea level $\mathrm{VO}_{2 \max }$ and endurance are not enhanced by acute hypobaric exposure. Eur J Appl Physiol 1997;76:8-12.

10. Messonnier L, Freund $\mathrm{H}$, Feasson L, et al. Blood lactate exchange and removal abilities after relative high intensity exercise: effects of training in normoxia and hypoxia. Eur J Appl Physiol 2001;84:403-412.

11. Rodriguez FA, Ventura JL, Casas M, Rama R, Viscor JL. Erythropoietin acute reaction and haematological adaptations to short, intermittent hypobaric hypoxia. Eur J Appl Physiol 2000;82:170-177.

12. Casas M, Casas H, Viscor JL, et al. Short-term intermittent exposure to hypobaric hypoxia and exercise induces haematological adaptations and acclimation. J Sport Sci 1998;16:450-451.

13. Masuda K, Okazaki K, Kuno S, Asano K, Shimojo H, Katsuta S. Endurance training under 2500m hypoxia does not increase myoglobin content in human skeletal muscle. Eur J Appl Physiol 2001;85:486-490. 
14. Rowell LB, Blackmon JR. Lack of sympathetic vasoconstriction in hypoxemic humans at rest. Am J Physiol 1986;251:562-570.

15. Hainsworth R, Drinkhill MJ, Rivera-Chira M. The autonomic nervous system at high altitude. Clin Auton Res 200;17:13-19.

16. Calbet JL,Roadegran G, Boushe R, Saltin B. On the mechanisms that limit oxygen uptake during exercise in acute and chronic hypoxia: role of muscle mass. J Physiol 2009;587(2):477-490.

17. Joseph V, Pequignot JM. Breathing at high altitude. Cell Mol Life Sci 2009;66(22):3565-73.

18. Semenza GL. HIF-1: mediator of physiological and pathophysiological responses to hypoxia. J App/ Physiol 2000; 88:1474-1480. 